\title{
Análise territorial no xiro espacial do coñecemento
}

\author{
Territorial analysis in the spatial turn of knowledge \\ RUBÉN CAMILO LOIS GONZÁLEZ \\ Universidade de Santiago de Compostela \\ https://orcid.org/0000-0003-4717-1061 \\ rubencamilo.lois@usc.es \\ LUCREZIA LOPEZ \\ Universidade de Santiago de Compostela \\ https://orcid.org/0000-0003-4451-6423 \\ lucrezia.lopez@usc.es \\ Mª́NGELES PIÑEIRO ANTELO \\ Universidade de Santiago de Compostela \\ http://orcid.org/0000-0002-8837-989X \\ manxeles.pineiro@usc.es
}

\section{RESUMO}

O pensamento contemporáneo referido á ciencia deu un xiro moi importante nos anos 1960 e 1970, sobre todo en Francia. Varios autores cuestionaron a preeminencia e inmutabilidade do discurso histórico. Nas súas obras comezaba a colocarse en primeiro termo a análise espacial e territorial crítica. Este proceso coñécese como o "xiro espacial" no coñecemento contemporáneo. A presente proposta epistemolóxica espacial e territorial é recollida na USC polo Grupo de Investigación ANTE (GI-1871) tratando de crear un potente polo de reflexión territorial no contexto universitario galego, ibérico e internacional. Trátase de estudar os grandes temas do mundo actual desde a perspectiva enmarcada na teoría social crítica. Os efectos da globalización e da urbanización, do cambio rural, do abandono e avellentamento, dos impactos ambientais, do turismo ou do desenvolvemento endóxeno e sustentable son temas centrais nunha abordaxe que sempre recorre á análise a diferente escalas.

Palabras clave: Análise espacial e territorial, pensamento contemporáneo, teoría social crítica, Grupo ANTE (GI-1871).

\section{Abstract}

Contemporary thought referring to science gave a very important turn in the 1960s and 1970s, especially in France. Several authors questioned the pre-eminence and immutability of historical 
discourse. In their works the critical space and the territorial analysis began to be the main concerns. This process is known as the "spatial turn" in contemporary knowledge. The present spatial and territorial epistemological proposal refers to the USC, namely the research group ANTE (GI-1871). It is trying to become a powerful referent for the territorial reflection in the Galician, Iberian and international university context. It is concerned with the study of the great issues of the current world from the perspective of the critical social theory. The effects of globalization and urbanization, rural change, abandonment and aging, environmental impacts, tourism or endogenous and sustainable development are central themes in an approach that always relies on analysis at different scales.

Keywords: Spatial and territorial analysis; Contemporary thought; Critical social theory, ANTE Research (GI-1871).

O pensamento contemporáneo referido á ciencia deu un xiro moi importante nos anos 1960 e 1970, sobre todo en Francia. Autores como M. Foucault, G. Deleuze, H. Lefebvre ou G. Debord cuestionaron a preeminencia e inmutabilidade do discurso histórico (Debord, 1967; Deleuze e Guatari, 1980; Foucault, 1969, 1978; Lefebvre, 1974). Ao mesmo tempo, nas súas obras comezaban a aparecer os conceptos de cidadanía, espazos acoutados, desterritorialización e reterritorialización, de-construcción, etc., que colocaban en primeiro termo a análise espacial e territorial crítica (Bauman, 1989; Deleuze e Guatari, 1980). Todo este proceso coñécese como o "xiro espacial" no coñecemento contemporáneo que acompañou á postmodernidade no seu combate contra os grandes relatos. Así, xeógrafos e sociólogos ilustres como D. Harvey. E. Soja, S. Sassen, Yi-Fu Tuan ou M. Castells animaron unha Xeografía distinta moi actual (Castells, 1974,1995; Harvey, 1990,2001; Sassen, 1991: Soja 1989,1996; Tuan, 1977).

Por outra banda, tres novidades recentes reforzaron aínda máis o papel central do espazo no pensamento social e científico desenvolvido nos últimos decenios. A primeira, a aparición do concepto antropoceno, que procura caracterizar a dinámica seguida polo planeta Terra nos últimos milenios, onde a actuación dos seres humanos se conceptúa como fundamental para entender as mudanzas acontecidas no medio físico e nos sistemas naturais: cambio climático, artificialización dos solos, destrución acelerada do patrimonio natural, alteracións rexionais acrecentadas dos ecosistemas, etc. (Latour, 1993; Revkin, 1992; Ruddiman, 2003). No antropoceno a acción humana e social ao longo da historia é quen condiciona a dinámica natural, o que volve situar o debate humano/físico fundamental na Xeografía desde a súa orixe como ciencia no centro do coñecemento actual. Isto é recoñecido xa por pensadores centrais do panorama filosófico-científico mundial como B. Latour, unha evidencia que consolida esta apreciación (Latour, 2015). O antropoceno substitúe ao holoceno, no que aínda as variables climáticas (sucesión de períodos fríos e cálidos), condicionaban a evolución humana (por exemplo, o proceso de neolitización).

A segunda novidade ven dada polo papel central da cartografía para o coñecemento e a conceptualización do mundo. O xeógrafo italiano F. Farinelli foi o primeiro en escribir sobre "a crítica da razón cartográfica", xogando co titulo do ilustre xeógrafo e filósofo pai da modernidade I. Kant (Farinelli, 2009). De feito, este autor chega a defender que 
desde a antigüidade grega a Xeografía axuda a construír o pensamento filosófico a partir de esquemas e mapas moi básicos que pretenden ordenar sobre un papel ou un pergamiño todo o que se sabe de distintos lugares e rexións, tanto no referido ás características da súa poboación, accidentes do relevo, riquezas ou cidades, entre outros datos. Xorde así unha forma de interpretar o mundo mediada pola cartografía, que intentará poñer orde no coñecemento das rotas comerciais na Baixa Idade Media ou na época dos descubrimentos, inventará América e os outros continentes (Farinelli, 2009). Cando a reprodución masiva de mapas e a súa popularización nas escolas se consolide nos séculos XIX e XX, a cidadanía aprenderá a ollar e a razoar sobre o conxunto do territorio, sobre a súas nacións ou localidades doutro xeito. Nós pensamos na actualidade nos problemas cotiáns e decidimos ao longo do día en función do que nos din mapas e planos, que constitúen unha forma de mediación precisa (e sempre manipulada) entre as persoas e o espazo que nos rodea ou os territorios aos que nos adscribimos.

A terceira cuestión a considerar refírese á redución efectiva das liñas de separación entre as diferentes Ciencias Sociais, Humanas e da Terra nos últimos decenios. Autores tan reputados da socioloxía como S. Sassen ou M. Castells son tomados polos xeógrafos como propios, convidados aos seus eventos como pertencentes a un mesmo ámbito de coñecemento. Xeógrafos tan populares como D. Harvey, E. Soja, D. Massey ou Yi-Fu Tuan son confundidos con economistas, antropólogos ou humanistas. Os debates sobre o antropoceno son lugar de encontro de ambientólogos, xeólogos, e economistas, e por suposto xeógrafos. E o que se debe valorar como moi importante, a Xeografía en numerosas ocasións sitúase no centro destes debates, entre aquelas disciplinas máis sociais e humanas, e as ciencias experimentais ou da natureza. Nun período de transferencias e intercambios multidiscipinares, a Xeografía reforza o seu papel atendendo ao carácter tradicional de coñecemento fronteirizo, con enormes puntos de contacto, con outros ámbitos do saber. Como complemento, no interior da propia ciencia xeográfica a unidade entre o social (dominante) e o natural, espacial ou territorial, refórzase fronte ás vellas interpretacións que definían una tendencia á escisión entre a Xeografía física e a humana, hoxe unidas por conceptos como o antropoceno e pola enorme renovación da teoría social crítica (Ortega, 2000).

\section{O XIRO ESPACIAL}

Baixo esta expresión tenta resumirse o apuntado nos parágrafos introdutorios, como a postmodernidade e o novo pensamento crítico colocan á Xeografía e aos seus temas de interese no centro das Ciencias Sociais e do coñecemento actual. Un patrimonio tan relevante para a nosa disciplina como a análise territorial a diferentes escalas adquire un protagonismo central nos últimos anos. Se nos centramos nos tres xeógrafos máis influentes desde mediados do século, D. Harvey, E. Soja e Yi-Fu Tuan (Benach e Albet, 2010; Harvey, 2001; Nogué, 2018), poderemos observar en concreto as contribucións que a Xeografía está facendo ao debate científico actual. 
Así, D. Harvey nunha prolífica obra de múltiples significados e enfoques propúxose interpretar a dinámica do capitalismo contemporáneo, reducindo as súas lecturas evolutivo-históricas ou economicistas e reforzando a compoñente espacial do mesmo. Deste xeito, o desenvolvemento desigual e combinado do modo de produción caracterizado, a íntima conexión entre a desposesión das sociedades do sur e a acumulación concentrada nas do norte, convértese nun eixo dos seus razoamentos. Non só isto, a análise dos procesos de acumulación desigual, o xogo da subordinación das riquezas naturais ao fluxos financeiros. A propia financiarización (capacidade das entidades bancarias privadas de producir diñeiro sen parar, de forma directa ou indirecta), como motor do funcionamento do sistema (Nova Iorque exportaba produtos manufactureiros e agrarios a Europa hai un século e agora exporta papel diñeiro ou bits, chegou a escribir). A necesidade que o capital xera de posuír e dominar espazos, a xeopolítica implícita neste proceso, e o continuo xogo escalas global, local e intermedias na dialéctica xerada. Nova Iorque e París, como construcións urbanas que reflicten o éxito do capitalismo triunfante, as xeografías do desperdicio e da crise como expoñentes doutros moitos estudos e conceptos que este profesor anglo-americano manexa sobre espazo e territorio como elementos decisivos do mundo actual.

Pola súa banda, E. Soja radicalizou aínda máis o "xiro espacial” na súa argumentación cando se referiu a que o lugar tivera máis importancia nalgunhas fases da evolución da humanidade que os propios avances tecnolóxicos ou os modos de produción definidos no materialismo histórico clásico. Exemplifica isto en relación cos achados arqueolóxicos no xacemento turco de Catalhoyuk, unha cidade de 7.000 anos de antigüidade que aparece como resultado do comercio, da súa situación inmellorable como lugar central dun amplo espazo. A partir da propia existencia dunha aglomeración humana prodúcese a innovación, os progresos socio económicos e non á inversa como tradicionalmente se opinaba (Benach e Albet, 2010). Xunto a esta contribución, enmarcada na trialéctica espacial reivindicada polo xeógrafo norteamericano, outros conceptos como postmetrópoli ou terceiro espazo compréndense nun reforzamento espacial da teoría materialista. Neste senso, mesmo E. Soja chegou a afirmar que O Capital de K. Marx era tan só un primeiro volume economicista dunha tentativa máis complexa de tres tomos, un dos cales se centraría no desenvolvemento rexional desigual; dito doutro xeito, nunha análise espacial do gran pensador alemán do século XIX. Aquí, Soja coincide con D. Harvey cando formulou unha lectura xeográfica completa do materialismo histórico xa nos finais dos 1970 (Harvey, 1976; Soja, 1989).

Por último, Yi-Fu Tuan recuperou o valor do lugar, un lugar con significado, con atributos vinculados a súa propia existencia e carácter (Tuan, 1974). A Xeografía é a forma que as sociedades humanas teñen de apropiarse do espazo, poñerlle nomes e outorgarlle cualificativos. Uns lugares que xeran todo tipo de sentimentos, agradables ou repulsivos, de medo ou acollemento, de inmediatez ou inmensidade. Uns lugares que foron cambiando ao longo da historia e das civilizacións, polo que o entrelazado xeohistórico, espacial e temporal, resulta plenamente coherente. En épocas máis recentes, Tuan volveu 
recuperar algúns dos seus intereses máis ambientalistas, xeomorfolóxicos, dos seus primeiros anos como investigador a través doutra obra emblemática denominada Escapismo (Tuan, 1998). Na mesma, formula unha teoría orixinal consistente en que a humanidade ao longo da historia sempre procurou progresar tecnicamente e, para este fin, desorganizar a natureza. Neste proceso, a natureza tenta recuperar o seu estado orixinario e debido a esta razón prodúcense catástrofes, acontecementos estruturais preocupantes (como o cambio climático) ou o xurdimento de epidemias e novas enfermidades. Por iso acuña o concepto de escapismo, como a tendencia dos humanos a escapar da lóxica ambiental fronte á natureza que sempre loita por recomporse.

Aparte destes tres autores centrais, o xiro espacial tamén se topa no novo protagonismo adquirido polas diversas escalas nas que se estrutura a realidade. As primeiras, as fundamentais para estruturar o coñecemento da realidade, a global e a local. A estas alturas do século XXI, ninguén pode negar que estamos inmersos nun proceso de globalización, que explica moitas dinámicas do mundo actual. A globalización faise evidente no funcionamento dun sistema económico entrelazado, capitalista e dominado polos fluxos financeiros, que se caracteriza pola concentración da riqueza e das decisións mundiais nun conxunto de bolsas de valores continuas ao longo do día (desde Toquio e Shanghai a Wall Street pasando polos mercados europeos), un amplo grupo de grandes bancos privados e de fondos de inversións, e os gobernos da grandes potencias que procuran con desigual éxito regular o funcionamento da economía. A globalización tamén é cultural e maniféstase de moi distintas formas: campionatos e competicións deportivas retransmitidas a todos os continentes; cantantes que producen videoclips descargados por decenas de millóns de persoas; semanas da moda e reprodución de formas estandarizadas de vestir; xeneralización do modo de vida urbano, etc. Sen dúbida, existe unha dimensión globalizada das nosas vidas á que non nos podemos subtraer e que os xeógrafos, xunto con outros científicos sociais, tratan de caracterizar (Zoido et al., 2013).

No plano oposto reforzouse a escala local-afectiva, a dos lugares onde actuamos de xeito cotián, na que están os nosos familiares e amigos. A dos lugares con dirección, significado e atributos concretos. A do barrio, o centro urbano, a aldea e a poboación de orixe, o centro comercial, os bares de confianza, o parque no que corremos, etc. Esta escala resulta fundamental para comprender moitos procesos elementais de socialización, para achegarse a temas xeográficos relevantes como o comportamento demográfico, a vivenda ou desprazamentos por motivo de compras, entre outros. Tamén se revalorizou na interpretación dos procesos electorais e da Xeografía política en xeral (Taylor, 1994), e serve de base para a construción de programas educativos baseados na aprendizaxe a partir do entorno máis próximo, o denominado coñecemento do medio, que permite o achegamento á Xeografía situando ao neno ou á nena e ao rapaz/a fronte a súa realidade espacial cotián, para logo manexarse ben nas escalas máis remotas, supralocais ou rexionais.

De feito, o terceiro nivel de análise xeográfica é o conformado polas escalas intermedias, normalmente rexionais. Estas escalas son unha construción humana, determinada polo período histórico onde nos encontremos e a sociedade de referencia. Permiten en- 
tender a estruturación da realidade actual en nacións, con todas as implicacións que isto implica a nivel político ou económico. Por suposto, xustifican a organización do noso espazo de actividade en áreas urbanas ou metropolitanas, en comarcas provedoras de determinados servizos públicos, ou en rexións máis ou menos amplas onde nos desprazamos e vivimos ao longo dunha semana ou dun mes. As rexións, as escalas supralocais, definen o terceiro nivel para interpretar a realidade territorial, aquel que varía segundo o período e as construcións espaciais fronte á que nos atopemos, pero non por iso constitúe un nivel menos relevante para encadrar o conxunto de actividades humanas. En boa medida, todas as escalas e delimitacións que se sitúan entre o global e o local reflicten o sistema socio político e a formación espacial onde nos movemos para comprender a organización territorial dunha etapa histórica determinada.

\section{O XIRO EPISTEMOLÓXICO}

Neste proceso de revalorización do discurso xeográfico, cumpre destacar dúas influencias teóricas moi importantes que condicionan a súa construción de coñecemento no presente. A primeira é a teoría social crítica, ligada directamente ao pensamento marxista occidental que se consolidou desde os anos 1980. A Xeografía interesase polas desigualdades espaciais, polos contrastes de riqueza e de apropiación dos territorios entre os seres humanos, pola perspectiva feminista e de xénero. Neste senso, autores como D. Harvey, D. Massey, E. Soja, N. Smith ou os brasileiros M. Santos e R. Haersbaert (Santos, 1996; Haersbaert, 2010), reivindican abertamente o legado do pensador alemán nado en Tréveris nos comezos do século XIX. Pero, tamén en todos os casos, toman as súas contribucións como un referente inicial, a partir do cal desenvolver novas ideas, matizar moitas opinións e elaborar argumentos flexibles, coherentes coa superación que o marxismo occidental fixo das estreitas lecturas materialistas dos anos 1960 e 1970 (Willians, 1980; Hobsbawn, 1997).

Do mesmo xeito que o pensamento xeográfico actual é hexemónicamente marxiano e crítico, o xiro cultural, postmoderno, nas Ciencias Sociais tamén se incorporou con forza na nosa disciplina. Unha Xeografía que, a pesar desta afirmación recorre nas súas ramas á cuantificación, medición e tipificación dos seus resultados, como acontece co manexo das TICs, e máis en concreto do SIX, en moitos estudos xeomorfolóxicos ou de Xeografía social, urbana e económica. O emprego de paradigmas analíticos e sistémicos continúa (Ortega, 2000), pero baixo unha corrente relativista e interpretativa dominante. Isto apreciouse claramente nas obras de D. Harvey ou E. Soja no tránsito dos 1980 a 1990 (Harvey, 1990; Soja, 1989), e dun xeito continuo no conxunto da obra de Yi-Fu Tuan. Tamén se corrobora no retorno ao interese pola paisaxe, como un dos eixos máis revalorizados na investigación e na práctica xeográficas. Por suposto, na aproximación constatable entre a Xeografía e a Antropoloxía, e no desenvolvemento e afondamento no emprego de métodos cualitativos na análise espacial e territorial. 
Un terceiro elemento a considerar refírese á marcada actualidade dos temas de investigación xeográfica no presente, non só a nivel xeral senón tamén na súa aplicación ao caso galego. Semella que a Xeografía se topase no centro das reflexións e debates da nosa sociedade. Por unha banda, o conxunto dos problemas ambientais globais, resumidos na alarma provocada polo cambio climático e o quecemento xeral do planeta. No noso país, isto ten consecuencias na modificación acelerada do nivel do mar, na maior irregularidade dos fenómenos meteorolóxicos e no control das emisións do CO2 á atmosfera (onde as centrais térmicas de As Pontes e Meirama encabezan as clasificacións de impacto de toda España). Por outra, o debate poboacional, centrado en temas tan relevantes como o avellentamento demográfico e as migracións, tanto da mozidade galega que debe partir para topar un emprego digno no exterior como de inmigrantes pobres que tratan de construírse un porvir entre nós. En terceiro lugar, a desarticulación do medio rural, expresada no carácter crónico e incontrolable dos lumes forestais, no sobreconsumo produtivista de auga ou no abandono de decenas de aldeas de todo o país. En cuarto termo, o descontrol do crecemento urbano e da artificialización masiva do litoral; a dificultade na súa regulamentación, os impactos paisaxísticos e a conxestión que xeran. Por último, e sen ánimo de ser exhaustivos, o debate sobre as infraestruturas de transporte ou a mobilidade, a necesidade de modelos sustentables da mesma, da fixación de obxectivos concretos para unha mellor accesibilidade ou conectividade, sen que estes supoñan enormes gastos en obras de enxeñería civil, como o paradigma dominante até agora tratou de afirmar.

De forma reiterada, a cuestión que se formula no quefacer investigador dos xeógrafos e dos analistas territoriais é como proceder para realizar os estudos. Qué recursos, fontes, procedementos, obxectivos, hipóteses e preguntas formular. En particular tendo en conta que os temas a abordar son moi amplos e que as metodoloxías a desenvolver adoitan ser variadas, a diferenza no que ocorre noutras ciencias. O xeógrafo e a xeógrafa móvense entre a cuantificación e o emprego de técnicas cualitativas, o recurso a escalas concretas, rexionais ou a un marco xeral de reflexión. Recorren tamén a figuras, imaxes, mapas e táboas, como expresión dos resultados. Polo tanto, resulta bastante difícil sintetizar as bases epistemolóxicas da ciencia xeográfica, os camiños seguidos para xerar coñecemento científico.

En primeiro lugar, e como adoita ser frecuente conforme nos achegamos ao presente, a análise territorial debe fundamentarse dun xeito sólido e completo en bases teóricobibliográficas solventes. Desde o punto de vista estritamente teórico xa nos referimos a autores moi significativos e a enfoques que, sen dúbida, se están empregando hoxe en día para facer Xeografía. Cumpre dicir que os fundamentos bibliográficos mudaron nos últimos tempos en tres direccións. Primeira, e de forma paralela a outras ciencias sociais, os libros e os tratados perden forza relativa fronte ao empuxe de artigos e textos breves publicados en importantes revistas de impacto global. Segunda, como consecuencia da anterior, recórrese a moita máis literatura científica publicada en inglés, e retrocede o uso dalgunhas linguas que foron moi influentes no pasado, como o francés. Terceira, as citas amplíanse, xeneralízanse, dado que se considera que calquera documento debe estar res- 
paldado por moita literatura previa. Como xa se insistiu en parágrafos previos, o recurso ao mapa e aos planos son fundamentais no coñecemento xeográfico. A razón da nosa disciplina é cartográfica e, ademais, esa cartografía é fundamentalmente temática, elaborada directamente para soster unha argumentación, para favorecer a análise en marcha. A este respecto, os xeógrafos e as xeógrafas diferenciámonos doutros especialistas (como, por exemplo, os arquitectos e enxeñeiros) polas escalas preferidas á hora de desenvolver os nosos estudos. Deste xeito, movémonos por escalas máis amplas, do 1:500 (fuxindo do proxecto arquitectónico) e chegamos sen dificultade á 1:50.000 característica dos primeiros mapas topográficos). No medio as 1:2.000 a 1:10.000 para as cidades e espazos urbanos, e as 1:20.000 ou 1:25.000 para ámbitos supralocais. Os mapas de representación rexionais, nacionais ou continentais tamén se empregan moito, pero cuns fins máis didácticos ou divulgativos, e menos analíticos.

Xunto á cartografía, a análise xeográfica non pode esquecer que se encadra no coñecemento científico de tipo social e territorial. Por iso, debe recorrer á produción regular de estatísticas oficiais e de series de datos contrastables e medibles. $\mathrm{O}$ acto de cuantificar, de crear indicadores e taxas sintéticas, de empregar as análises factoriais e as representacións gráficas de modelos analíticos complexos, forma parte dos quefaceres xeográficos. De xeito especial, nos estudos de Xeografía física, cando se utilizan os Sistemas de Información Xeográfica (SIXs) ou se procuran realizar caracterizacións rexionais e locais ben argumentadas. O xeógrafo e a xeógrafa organiza parte dos seus saberes sustentándoos na estatística. Volvendo a un argumento anterior, faino mediante a estruturación da súa pescuda a diferentes escalas, desde a micro de barrios ou seccións censuais nas cidades e das parroquias no rural até a macrorexional ou estatal pasado pola municipal, supralocal (áreas metropolitanas e comarcas) e rexional, nos seus múltiples significados.

A cuantificación é unha parte da base investigadora, pois a Xeografía tamén utiliza moito a aproximación cualitativa. Podería dicirse que cada vez máis, resultado do apuntado xiro cultural no coñecemento e na aproximación que se deu en épocas recentes á antropoloxía. A análise territorial gusta das entrevistas, do contacto directo cos actores e do emprego das categorías lingüísticas e representativas nos seus estudos. Isto compróbase nunhas renacidas Xeografía cultural e social, nos estudos urbanos e migratorios e mesmo nas novas liñas emprendidas pola análise climática ou das augas. A paisaxe, a súa revalorización recente e consideración como obxecto a protexer, tamén contribuíu moito á valorizar o perceptivo, o intanxible e o cualitativo.

Por último, o esforzo científico, de xeración de coñecemento xeográfico, nunca pode circunscribirse ao gabinete, ao despacho ou ás consultas nos arquivos. Necesita da observación participante no exterior, das visitas e saídas organizadas; en definitiva, do traballo de campo. Saíndo fora dos espazos cotiáns de traballo é posible comprobar dinámicas xeomorfolóxicas, rexistrar a variabilidade dos tipos de tempo, medir ríos e regatos, elaborar informacións dirixida aos catálogos da paisaxe e precisar as cuncas visuais, observar a organización do espazo agrario, as características dominantes da morfoloxía 
urbana e, como antes comentabamos, falar coas xentes, cos habitantes do lugar. A investigación sobre o terreo ven sendo fundamental na Xeografía contemporánea e completa uns métodos de investigación, unha formulación epistemolóxica do coñecemento xeográfico, diversa, xa que a análise territorial aborda un conxunto complexo de cuestións referidas a unha realidade, a organización do espazo, tamén polisémica.

\section{A CONTEXUALIZACIÓN EN GALICIA A TRAVÉS DO GRUPO ANTE}

Esta proposta epistemolóxica espacial e territorial é recollida na Universidade de Santiago de Compostela polo Grupo de Investigación ANTE (GI-1871), que se interesa por estudar os grandes temas do mundo actual e que afectan a Galicia, as súas cidades e concellos, desde a perspectiva enmarcada na teoría social crítica. Deste xeito, os efectos da globalización e da urbanización, do cambio rural, do abandono e avellentamento, dos impactos ambientais, do turismo ou do desenvolvemento endóxeno e sustentable, son temas centrais nunha abordaxe que sempre recorre á análise a diferente escalas. Os enfoques marxiano e dos estudos culturais contribúen a formular esta liña investigadora que se traduce, seguindo a B. Latour (1993) sobre as formas de acumulación capitalista na produción de coñecemento, na publicación en editoras e revistas de impacto, na obtención de proxectos e contratos de investigación competitivos ou na dirección de Teses. Todo iso, co obxectivo de crear un potente polo de reflexión territorial no contexto universitario galego, ibérico e internacional.

A metodoloxía empregada para afrontar o caso de estudo concretado no Grupo ANTE consistiu en analizar elementos chave como a súa composición, as liñas de investigación prioritarias e os enfoques de achegamento aos temas. Esta primeira aproximación máis cualitativa completouse co estudo dunha serie de indicadores cuantitativos, relacionados coa produción científica do grupo, e coa súa participación en proxectos, e contratos de investigación. Por último, o estudo completouse co afondamento en dúas liñas de traballo de gran importancia e tradición grupo, concretamente no Camiño de Santiago e na Xeografía da Pesca.

\subsection{O Grupo Ante (GI-1871): Grupo de Investigación en Análise Territorial}

ANTE é un grupo interdisciplinar de docentes e investigadores da Universidade de Santiago de Compostela (USC). Formado por xeógrafos, economistas, arqueólogos, historiadores e arquitectos, os membros do grupo ANTE están integrados en catro departamentos da USC: Xeografía, Economía Aplicada, Organización de Empresas e Comercialización, e Didáctica da Lingua e Literatura e das Ciencias Sociais. Os seus membros imparten docencia en universidades galegas, españolas e estranxeiras e acumulan experiencia profesional fóra do ámbito académico e investigador, como planificadores e xestores en organismos vinculados ao desenvolvemento rexional e local. Por outra banda 
tamén exercen cargos de representación e xestión en organismos de carácter xeográfico a escala nacional e internacional, como a Unión Xeográfica Internacional (IGU), a Asociación de Xeógrafos Españois (AGE), ou a Delegación Galega do Colexio de Xeógrafos. Unha das súas fortalezas é a súa profunda coherencia interna, derivada do feito de que gran parte dos seus membros veñen desenvolvendo a súa traxectoria investigadora no grupo desde a etapa de estudantes. Os membros máis novos, formáronse dentro do grupo como estudantes e investigadores pre e posdoutorais. Pero tamén o grupo benefíciase da incorporación de novos profesores e investigadores, procedentes de Universidades españolas e estranxeiras, que aportan novas ideas, métodos e maneiras de pensar e organizarse, coas vantaxes que supón iso para o conxunto. Trátase de exemplos como os dos profesores Valeriá Paül Carril, formado na Universidade de Barcelona, e Juan Manuel Trillo da Universidad Carlos III de Madrid, e dos investigadores posdoutorais Lucrezia Lopez, formada na Università degli Studi di Bari (Italia), Yamilé Pérez Guilarte, da Universidade de La Habana (Cuba). Tamén se teñen incorporado investigadores nas primeiras etapas da súa formación como Iago Lestegás, formado na Universidad Politécnica de Madrid, ou Inês Gusman, na Universidade do Minho. No ano 2018 o grupo está composto por 24 membros, dos que 8 son mulleres. Dentro do mesmo, 16 membros son Persoal docente e investigador (PDI), 4 investigadores en formación, e 4 que traballan como persoal de apoio. Conta ademais o grupo ANTE con colaboradores externos de universidades españolas e estranxeiras, entre os que destacan profesores e investigadores de universidades brasileiras, cos que existen numerosas canles de colaboración. Ten a súa sede no Instituto Universitario de Estudos e Desenvolvemento de Galicia (IDEGA), o que favorece o contacto cos outros grupos de investigación da USC, e colabora de maneira habitual con outros centros desta Universidade, como o Centro de Estudos e Investigacións Turísticas da USC (CETUR) ou a Fundación de Estudos EuroRexionais (CEER), ambos dirixidos por membros do grupo. $\mathrm{O}$ achegamento a estas entidades favorece o acceso ao coñecemento interdisciplinar, a fontes de financiamento, e a integración en redes de traballo, ás que lle sería máis difícil chegar de forma individual. A constitución de redes de investigación en Ciencias Sociais fortes e con carácter multidisciplinar é un dos obxectivos do grupo ANTE, e por iso promove e se integra no agrupamento estratéxico BETA +, constituído por 16 grupos de investigación da USC, máis outros grupos do Sistema Universitario Galego (SUG), ao que se suma o Centro de Investigacións Agrarias de Mabegondo, dependente da Consellaría do Medio Rural.

\subsection{A acumulación capitalista do coñecemento: proxectos, publicacións, teses e contratos de investigación do grupo ANTE}

A globalización faise evidente tamén no funcionamento dos sistemas universitarios de investigación e innovación, e como resultado prodúcese un crecemento do tamaño dos grupos co obxectivo de reforzar a súa capacidade de afrontar os retos de sociedades cada vez máis complexas. As políticas europeas, estatais e rexionais de fomento da investi- 
gación favorecen o desenvolvemento de unidades de investigación fortes, multidisciplinares, que dedican parte dos seus esforzos á transferencia de coñecemento e tecnoloxía. Para adaptarse a esta tendencia o grupo ANTE ten experimentado unha evolución desde a súa creación centrada en 3 aspectos fundamentais:

I. Aumento do número de membros e reforzo do peso dos investigadores novos desde un punto de vista cuantitativo. Precisamente esta nova xeración de investigadores ten sido recoñecida a nivel nacional e internacional con premios á investigación en diferentes temáticas. Exemplos destacados son o galardón Jesús García Calvo para investigacións en desenvolvemento rural e cooperación, o Premio Roser Majoral Moliné da AGE, o Best Paper Award no Encontro anual IGU Urban Geography Commission 2017, ou o premio Valeria Morabito ICT and Heritage con ocasión do Congreso Internacional $3^{\text {rd }}$ New Metropolitan Perpective 2018.

II. Internacionalización do grupo tanto pola incorporación de colaboradores estranxeiros como pola participación en consorcios internacionais de investigación, ou como polo aumento da produción científica e da actividade investigadora a escala internacional e nacional.

III. Incorporación de enfoques e liñas de investigación novidosas e de carácter fortemente pluridisciplinar, froito da propia incorporación de novos investigadores, e pola dirección de teses no marco do grupo.

Esta profunda evolución resultou moi favorecida, e condicionada, pola chegada de fondos públicos ao grupo, procedentes de programas e convocatorias autonómicos, estatais e internacionais. Estes recursos financeiros destináronse a consolidar a figura do tecnólogo no grupo, e a transferir os resultados da investigación, asistindo a congresos e reunións nacionais e internacionais. $\mathrm{O}$ efecto deixouse sentir na capacidade do grupo para a creación e xestión de consorcios de grupos de investigación para concurrir a convocatorias de proxectos europeas, no aumento do seu número de publicacións en revistas de impacto, na posibilidade de participar en redes de investigación e docencia a nivel internacional, e na presenza en comités editoriais de numerosas revistas científicas. Por outra banda, o grupo ANTE puido iniciar unha traxectoria como organizador e financiador de bolsas de colaboración, seminarios, xornadas e visitas de expertos de referencia mundial que reforzaron a posición do grupo non só na USC, senón tamén a escala galega e estatal. Podemos citar como exemplos o II Congreso Internacional SETED-ANTE "Seminario Estado, Territorio e Desenvolvemento", celebrado en 2015, ou o 26th Annual Colloquium of the Commission on the Sustainability of Rural Sysmtes da IGU, celebrado no 2018.

Entre os fondos chegados ao grupo, resultaron de especial relevancia os de carácter autonómico, nunha tripla vertente: 
I. Desde o inicio do programa en 2009, o grupo recibe as axudas para a consolidación e estruturación das Unidades de Investigación do Sistema Galego de I+D, o que favorece o desenvolvemento da súa vocación internacional.

II. Desde a súa primeira edición en 2011, sete doutores formados no ámbito do grupo, obtiveron unha axuda de apoio á etapa de formación posdoutoral nas universidades doSUG. En virtude destas mesmas axudas, na convocatoria de 2014 sumouse ao grupo unha nova doutora, procedente do Departamento de Ciencias da Terra da Universidade de Illes Balears, o que permitiu reforzar a liña de investigación centrada na análise dos procesos de segregación socioespaciais en áreas urbanas.

III. O grupo ANTE lidera a rede de investigación "Novos enfoques da Análise Territorial: implicacións sociais, económicas e formativas"(NEDAT), que se ten beneficiado das axudas para Redes das Convocatorias de Consolidación da Xunta de Galicia desde 2014. A rede NEDAT agrupa a profesionais das Ciencias Sociais interesados en estudar as implicacións territoriais da sociedade, e economía e a educación. Inicialmente estaba formada por 4 grupos de investigación da USC e da UdC, e centrada en temas como o crecemento intelixente, sustentable, e inclusivo, as smart cities, a relación entre turismo, patrimonio, e paisaxe ou a educación como motor de crecemento intelixente. Desde 2016 incorporáronse 2 grupos máis da USC, especializados en métodos cuantitativos e empresas agroalimentarias, e en valoración financeira aplicada.

Xa no ano 2011, pero sobre todo desde 2012, o Grupo ANTE iniciou unha estratexia de intensa concorrencia a convocatorias europeas, tanto en liñas de investigación xa coñecidas polo grupo, como en outras de carácter moi innovador. Así, nos últimos anos presentáronse propostas no marco de varios Programas europeos. Como resultado, o grupo ten liderado o proxecto ESPON European Regions: potencial contribution to the EU 2020 Strategy. Spatial Indicators for a Europe 2020 Strategy (111_PR1_18_0387), e participado no ESPON Action 2.1.5: Territorial Impacts of European Fisheries Policy (2004-2005), membros do grupo participan no Programa European Cooperation in Science and Technology (COST) a través da Acción COST A European network to improve understanding and use of the ground beneath our cities (SUB-URBAN); no Programa Erasmus +, a través dos proxectos Urban Dynamics: Global Perspectives for a Socio-Cultural Urban Management (URBDYN), coa Universidade de Kiel como xefe de filas, e Patrimoine Européen pour un Avenir Culturel Ensemble (PROPEACE), liderado pola Universidade Jean Monnet - Saint-Etienne; e no INTERREG V (2014-2020), Programa de Cooperación Transfronteiriza España-Portugal, a través do proxecto Patrimonio Colectivo Cultural: Plataforma para la valorización e Innovación (GEOARPAD).

A escala estatal, o grupo Ante leva participando desde a súa creación en convocatorias do ministerio de Economía e Competitividade, e resulta significativo que desde o 
ano 2010 se teñan desenvolvido tres proxectos consecutivos, os últimos na Convocatoria de Retos para a Sociedade, que tratan de afondar no estudo do sistema metropolitano español, na súa evolución e retos, con especial incidencia nas cidades galegas: (1) Sistema de indicadores para el análisis de las dinámicas urbanas y metropolitanas en España a comienzos del siglo XXI (CSO2010-16298); (2) Los retos del sistema metropolitano español ante la Estrategia Europea 2020 en un contexto de crisis. La consolidación de un observatorio urbano y metropolitano (CSO2013-47833-C4-1-R) e (3) Nuevos modelos de gobierno de las ciudades, e intervención en los espacios urbanos en el período postcrisis (CSO2016-75236C2-1-R). Estes proxectos permitiron integrar no equipo de traballo a investigadores de universidades galegas, españolas e a expertos internacionais de México, Canadá e Francia, o que sen dúbida permitiu ao grupo reforzar a súa capacidade de traballo en equipo e de liderado.

Tamén resultan de gran interese para o grupo os proxectos financiados pola Agencia Española de Cooperación Internacional (AECID), pola novidade que supuxo iniciarse en proxectos de cooperación interuniversitaria e investigación científica en África Occidental, e polo desafío de traballar en países como Senegal, Cabo Verde, Níxer ou Mali. Trátase das dúas edicións do proxecto Diseño de instrumentos económico-territoriales para la gestión administrativa del desarrollo local en Senegal, Cabo Verde y Mali (A/23313/09 e A/030061/10), e do Proxecto Máster Internacional en Planificación, Desarrollo Local y Ordenación del Territorio en África Occidental (A1/037585/11).

Por último, a nivel autonómico, o grupo de investigación ten estado moi activo e participe nas políticas de planificación turística da Comunidade galega. A través do Centro Universitario de Estudos Turísticos (CETUR), dirixido nos últimos anos por membros do Grupo ANTE, participouse en, varios observatorios turísticos, como o Observatorio do Camiño de Santiago por encargo da S. A. Xacobeo, e desenvolvido entre 2006 e 2010, ou os estudos de viabilidade para a posta en marcha do Observatorio Turísticos de Galicia en 2004, encargado pola administración autonómica. Así mesmo, deseñáronse e puxéronse en marcha outros observatorios turísticos, de variable entidade e recorrido, como os das cidades de Lugo (desde 2004), Santiago de Compostela (desde 2005) e Ferrol (desde 2008), por encargo dos respectivos concellos.

O aumento considerable da produción científica do grupo nos últimos anos queda reflectida na seguinte táboa de indicadores (Táboa 1), tanto a partir de publicacións en revistas indexadas, como a través de libros e traballos en congresos internacionais. Por outra banda, desde o ano 2011 téñense defendido 20 teses doutorais dirixidas por membros do grupo, 7 de elas elaboradas por investigadores estranxeiros. No ano 2017 estaban a dirixirse 33 teses, e 15 dos doutorandos eran estranxeiros. 
Táboa I. Indicadores relativos ao grupo ANTE

\begin{tabular}{|c|c|c|c|}
\hline Indicadores & 2011 & 2016 & 2017 \\
\hline $\mathrm{N}^{\mathrm{o}}$ de IPs activos no grupo. & 12 & 18 & 16 \\
\hline $\mathrm{N}^{\mathrm{o}}$ de mulleres IP no grupo. & 4 & 5 & 5 \\
\hline $\mathrm{N}^{\mathrm{o}}$ de investigadores predoutorais incorporados. & 3 & 2 & 0 \\
\hline $\mathrm{N}^{\mathrm{o}}$ de investigadores postdoutorais incorporados. & 2 & 8 & 7 \\
\hline $\mathrm{N}^{\mathrm{o}}$ de tesis doutorais que se están a dirixir. & 32 & 35 & 33 \\
\hline $\mathrm{N}^{\mathrm{o}}$ de tesis doutorais defendidas. & 1 & 4 & 3 \\
\hline $\mathrm{N}^{\mathrm{o}}$ de investigadores visitantes. & 4 & 5 & 14 \\
\hline No de técnicos de apoio á investigación contratados. & 3 & 4 & 3 \\
\hline $\mathrm{N}^{\mathrm{o}}$ de proxectos en convocatorias competitivas autonómicas. & 1 & 2 & 4 \\
\hline $\mathrm{N}^{\mathrm{o}}$ de proxectos en convocatorias competitivas estatais. & 2 & 2 & 2 \\
\hline $\mathrm{N}^{\mathrm{o}}$ de proxectos en convocatorias competitivas europeas. & 0 & 4 & 5 \\
\hline No de publicacións en revistas SCOPUS ou Web of Science. & 5 & 23 & 26 \\
\hline No de libros, monografías e capítulos de libros. & 29 & 22 & 29 \\
\hline $\mathrm{N}^{\mathrm{o}}$ de traballos presentados en congresos/conferencias internacionais. & 5 & 52 & 32 \\
\hline$N^{o}$ de proxectos en colaboración con outros grupos estatais. & 1 & 9 & 7 \\
\hline Nº de publicacións en colaboración con outros grupos estatais. & 6 & 11 & 21 \\
\hline $\mathrm{N}^{\mathrm{o}}$ de proxectos en colaboración con grupos estranxeiros. & 1 & 5 & 5 \\
\hline No de publicacións en colaboración con grupos estranxeiros. & 3 & 4 & 15 \\
\hline $\mathrm{N}^{\mathrm{o}}$ de traballos presentados en congresos/eventos internacionais. & 7 & 34 & 41 \\
\hline $\mathrm{N}^{\mathrm{o}}$ de doutorandos estranxeiros. & 13 & 14 & 15 \\
\hline $\mathrm{N}^{\mathrm{o}}$ de investigadores visitantes estranxeiros. & 3 & 5 & 14 \\
\hline $\begin{array}{l}N^{o} \text { de membros que realizaron estadías de investigación en centros } \\
\text { estranxeiros. }\end{array}$ & 3 & 8 & 8 \\
\hline $\begin{array}{l}N^{o} \text { de contratos e convenios de investigación con outros axentes } \\
\text { (administración pública, terceiro sector, etc.). }\end{array}$ & 3 & 11 & 8 \\
\hline $\mathrm{N}^{\mathrm{o}}$ de congresos internacionais organizados. & 0 & 7 & 3 \\
\hline $\begin{array}{l}N^{o} \text { de seminarios/cursos/simposium de difusión de resultados } \\
\text { organizados }\end{array}$ & 5 & 8 & 15 \\
\hline
\end{tabular}

Fonte: Elaboración propia a partir da información proporcionada pola Secretaria Xeral da USC. 


\subsection{Enfoques e liñas de investigación novedosas e pluridisciplinares}

As investigacións desenvolvidas no marco do grupo teñen en común o seu carácter multidisciplinar desde dunha análise espacial e territorial crítica. As liñas de especialización abórdanse desde a Xeografía social, urbana e económica, tamén desde a Xeografía cultural e desde as perspectivas feminista e de xénero. O desenvolvemento socioeconómico e as desigualdades espaciais xeradas polo turismo, industria, transportes, pesca, así como os problemas ambientais derivados destas actividades son obxecto de estudo. Como tamén o son o desenvolvemento local, o urbanismo e á ordenación do territorio, e os problemas asociados á mobilidade e á cooperación internacional ao desenvolvemento.

As teses de doutoramento desempeñan un papel importante no marco do grupo, pois a través das mesmas explóranse novas linas de investigación e fortalécense as relacións interdepartamentais e internacionais, como no caso da tese en co-tutela de José Ignacio Vila, defendida na Universidade Paris 1- Panthéon-Sorbonne. Ademais, o factor internacional queda reflexado nos mesmos títulos de doutores, pois grazas as estadías realizadas durante as etapas doutorais, o grupo conta coa presenza de Doutores Europeos e Doutores Internacionais.

Neste artigo tentamos exemplificar este enfoque pluridisciplinar e transversal a través da consideración de dúas liñas de presentes no grupo desde o seu inicio, pero que teñen sido obxecto de abordaxes novidosas.

\subsubsection{O Camiño de Santiago de Compostela}

Dende sempre o Camiño de Santiago representa una liña de investigación do grupo, que ten sido abordada desde enfoques distintos: Xeografía do turismo, Xeografía cultural, Xeografía urbana e na actualidade estase a explorar as súas relacións coas Xeo-humanidades. Os resultados foron, e son, estudos nos que se tenta por en relación a Xeografía coa Economía, a Socioloxía, a Historia, a Historia da Arte, a Antropoloxía e a Relixión. Tamén as teses de doutoramento defendidas no marco do grupo amosan este interese científico polo fenómeno xacobeo. Como exemplos, a tese de David Santomil Mosquera A imaxe exterior de Galiza no século XXI (2012), onde se analiza en profundidade a promoción de Galicia a nivel internacional, e se pon de manifesto a función atractiva do Camiño como produto estrela do turismo galego. Ou a tese de Lucrezia Lopez La imagen de Santiago de Compostela y del Camino en Italia. Una aproximación desde la geografía cultural (2012), onde se adoptan a perspectiva da Xeografía das peregrinacións e dos espazos sagrados para abordar a difusión do culto xacobeo no país italiano. Nese traballo explóranse fontes e metodoloxías habituais noutras disciplinas como a Historia, analízanse legados e testamentos de peregrinos ou ben textos da literatura odepórica. Esas fontes son empregadas para estudar os impactos territoriais do culto e os resultados plásmanse nos seguintes mapas. 


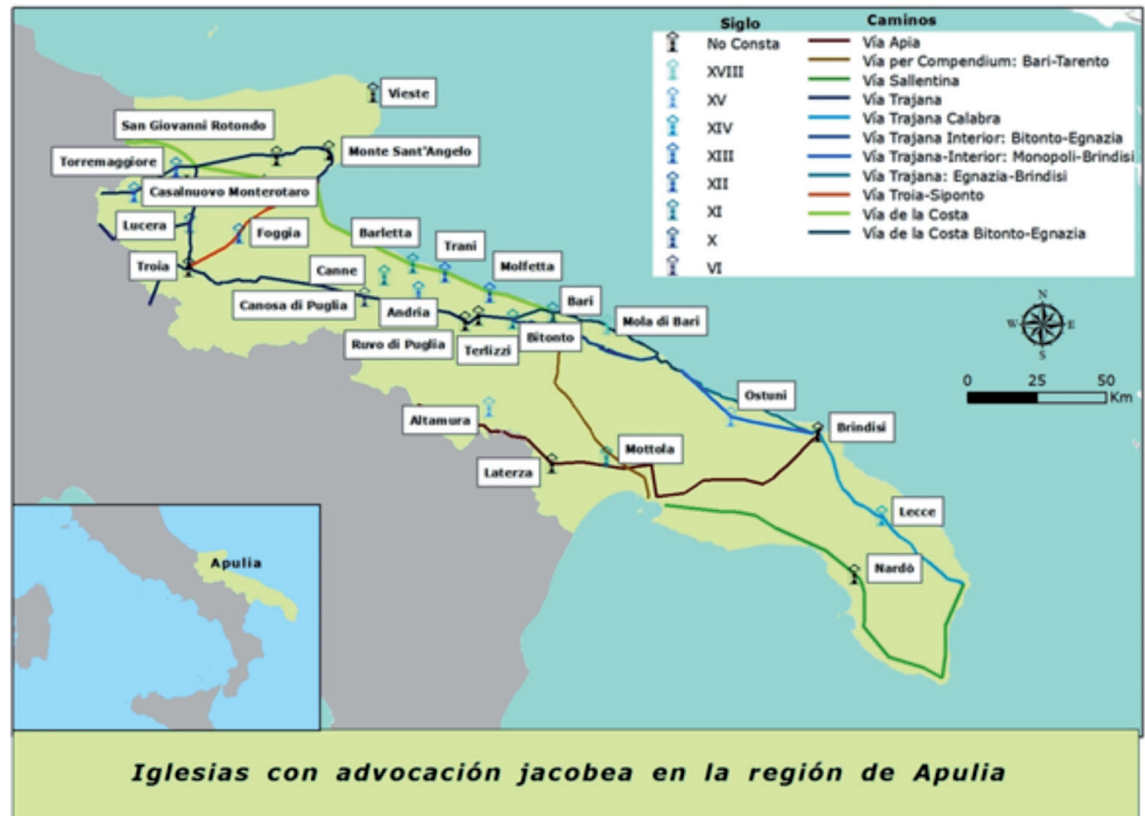

Figura 1. Difusión do culto xacobeo na rexión italiana de Apulia.

Fonte: Lopez, 2013, p. 331.

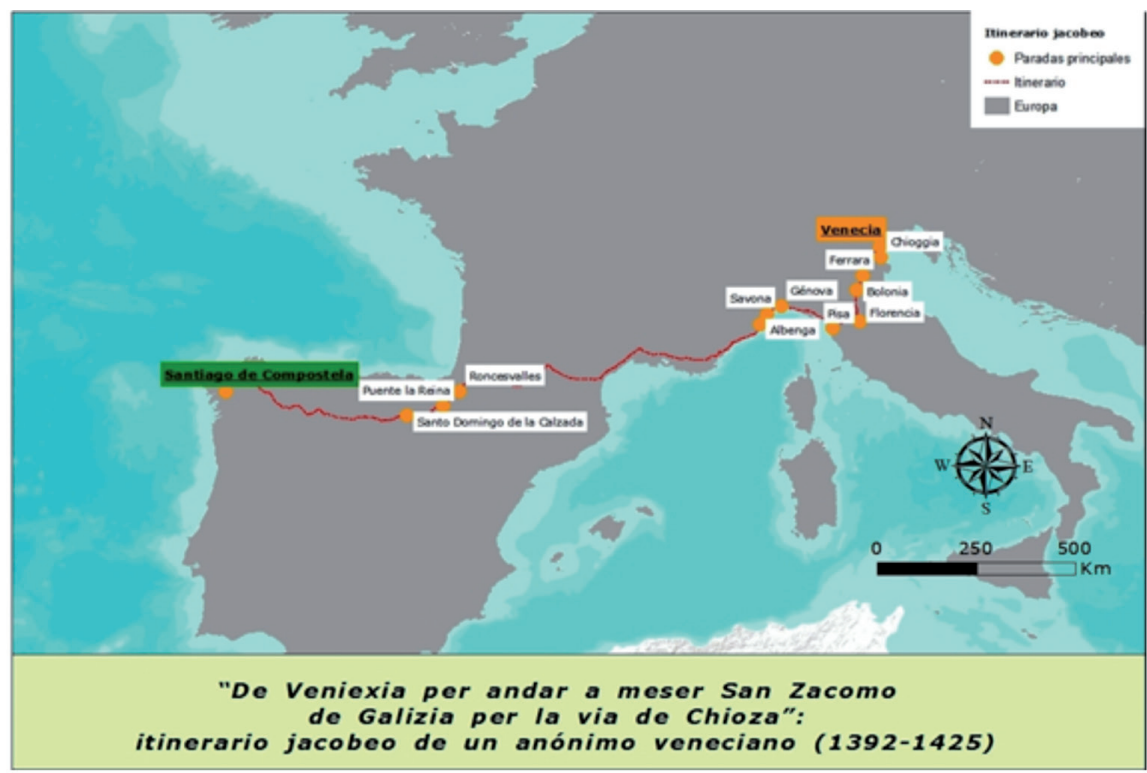

Figura 2. Itinerario de peregrinación do mais antigo relato italiano da peregrinación compostelana: De Veniexia per andar a meser San Zacomo de Galizia per la via de Chioza (1392-1425). 
Outros exemplos de teses de doutoramento que teñen investigado o Camiño de Santiago son a de Miguel Nuno Marques Pereira: Sistemas de Información Xeográfica e realidade aumentada en Turismo: Guía interactiva do Camiño Portugués de Santiago en Barcelos (2014), e de maneira tanxencial a tese de Pilar Taboada de Zúñiga: O Turismo Idiomático en Santiago de Compostela (2014).

As publicacións dos últimos anos en revistas internacionais apoian o interese cara o feito xacobeo, como o proban varios artigos en Mobilities, Culture and Religion: An Interdisciplinary Journal, Journal of Tourism and Cultural Change, Gender-Place and Culture, AlmaTourism. Journal of Tourism, Culture and Territorial Development ou Tourism Management Perspectives.

$\mathrm{Na}$ actualidade, o Camiño segue sendo uno dos focos da investigación do grupo, de feito, no marco do proxecto INTERREG GEOARPAD, estanse levando a cabo o suproxecto Piloto 2: Camiño de Santiago na área transfronteiriza Galicia-Norte de Portugal. O mesmo estruturase en tres accións: Acción 1. Investigación e catalogación dos elementos intanxibles do Camiño Portugués vinculados ao turismo cultural; Acción 2. Xestión de datos e transferencia na plataforma; Acción 3. Avaliación e planificación interpretativa do patrimonio intanxible do Camiño Portugués na rexión transfronteiriza Galicia-Norte de Portugal.

\subsubsection{A pesca}

A limitada abordaxe da temática marítimo-pesqueira por parte da Xeografía, tanto a escala rexional, como estatal, ten sido unha liña de estudo en si mesma dentro do grupo (Duran et al, 1998; Lois, 1999; Piñeiro e Lois, 2018; Santos, 2001). Neste marco, o auxe dos estudos relacionados coa actividade pesqueira tivo lugar entre os anos 2005 e 2007, cando se celebraron unha serie de reunións científicas que actuaron como catalizadores desta temática. Son de destacar as tres edicións sucesivas do congreso internacional "Globalización, Arraigo Xeográfico e Comunidades Costeiras en tempos de cambio", que permitiu ademais reforzar os lazos de colaboración entre os departamentos de Xeografía das Universidades de Bergen (Noruega) e Santiago (Piñeiro e Lois, 2018). Nos últimos anos, a defensa de teses no marco do grupo e a incorporación de investigadores posdoutorais ao departamento, reforza as investigacións nesta temática en colaboración con departamentos de Xeografía do resto de España, Portugal e Irlanda. As abordaxes desta temática realízanse desde Xeografía rural, os estudos de Desenvolvemento Rural, desde os estudos de Gobernanza, pero tamén desde o enfoque novidoso da Investigación e Innovación Responsables (RRI).

Proxectos de investigación como o ESPON Action 2.1.5: Territorial Impacts of European Fisheries Policy (2004-2005) ou o Proxecto financiado polo Fondo Social Europeo SEREA, Actividades complementarias da Pesca e do Marisqueo (2006-2008) mantiveron ao grupo ANTE entre os consorcios punteiros que estudaban as implicacións das políticas sectoriais de pesca no territorio a escala europea. Pero tamén o grupo mantíñase atento á realidade española e galega, como proba o contrato coa Dirección Xeral de Turismo da 
Xunta de Galicia para a realización do Estudo sobre o turismo pesqueiro. Exemplos de boas prácticas desenvolvidas en España (2006).

Por outra banda, teses como a de María de los Ángeles Piñeiro, centrada na Política Pesqueira Común e as comunidades costeiras de Galicia (2015), e publicacións relacionadas coa pesca e as comunidades costeiras seguen a manter viva esta liña de investigación dentro do grupo (Felicidades e Piñeiro, 2017; Piñeiro e Lois, 2018; Piñeiro, Durán e Santos, 2018; Piñeiro, Felicidades e O’Keefe, 2018).
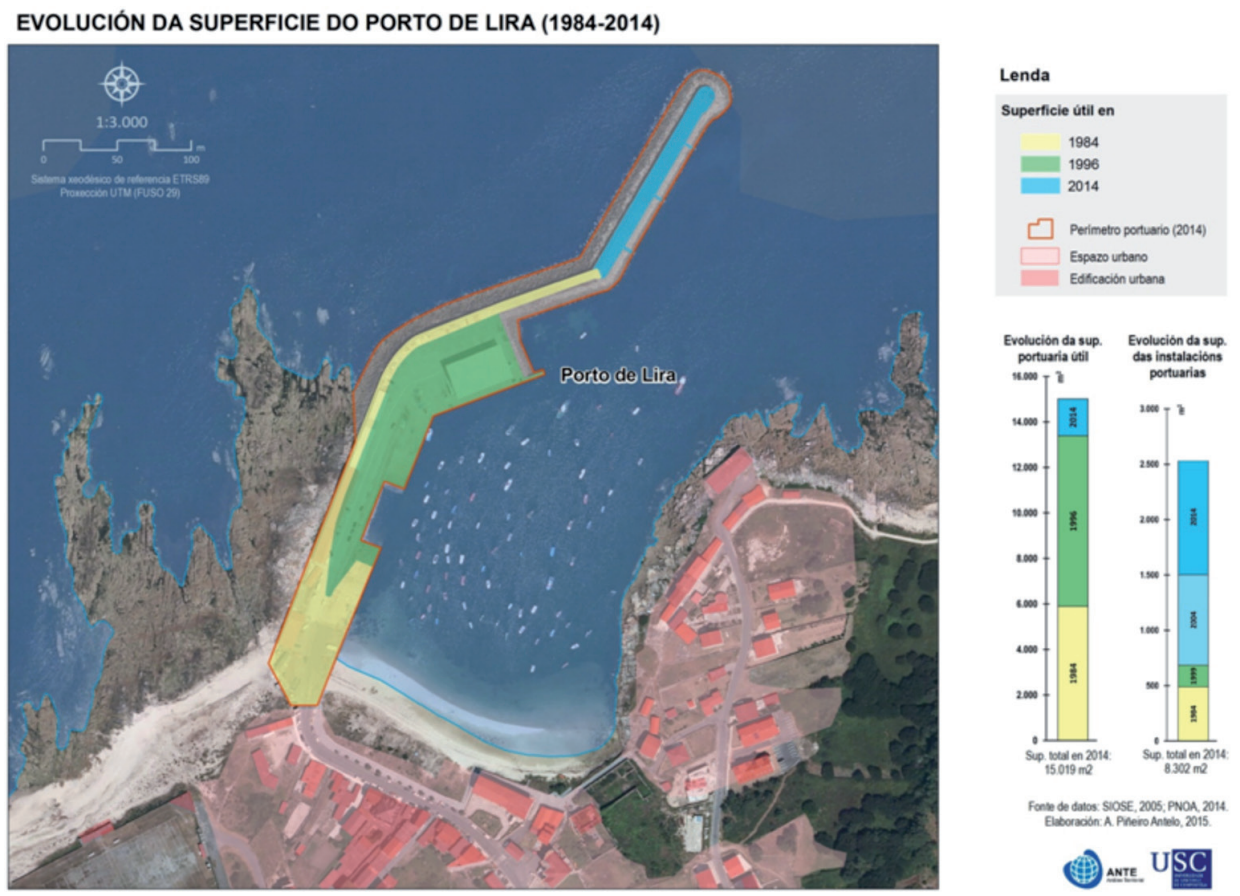

Figura 3. Evolución da superficie do porto de Lira (A Coruña).

Fonte: Piñeiro, 2015

Na actualidade o grupo colabora na redacción do Pacto Local polo Territorio Costeiro Sostible, coordinado polo Grupo de Acción Local Pesqueira (GALP) Costa Sostible, unha estratexia de desenvolvemento para esta zona de pesca no litoral da provincia da Coruña.

\subsection{Estratexia de futuro: cara a un polo de reflexión territorial no contexto univer- sitario galego, ibérico e internacional}

O grupo Análise Territorial, ten como obxectivo avanzar nas súas liñas de investigación clásicas, onde se incorporaron as prioridades establecidas nos documentos de 
planificación da I+D+i para os próximos anos, tanto a nivel europeo (Horizonte 2020, Investigación e Innovación Responsables), como español e galego (RIS3 Galicia, Estratexia Galega de Desenvolvemento Sostible (EGDS), Plan Director do Camiño de Santiago). Son as relacionadas co desenvolvemento sostible, a ordenación do territorio, os estudos urbanos, o turismo como factor de desenvolvemento territorial, as actividades relacionadas coa pesca, ou a xestión integral de zonas costeiras. Asemade, traballase para mellorar o proceso de formación doutoral e posdoutoral de cada membro do grupo, reforzando as ligazóns entre os métodos de ensino e as novas tecnoloxías, obxectivo definido na estratexia da Unión Europea para o Ensino Superior. Estes obxectivos xerais poden concretarse en obxectivos específicos que marcan o traballo do grupo de cara ao futuro:

I. Avanzar na estratexia de internacionalización destinada a reforzar o peso específico do grupo no ámbito da Xeografía e das Ciencias Sociais.

As relacións internacionais do grupo tratarán de formalizarse a través da sinatura de convenios e protocolos de colaboración con universidades e institucións estranxeiras. Neste camiño, o grupo ANTE -polo de referencia en España da Ano Internacional do Coñecemento Global (2017-2018)- apoia agora a declaración do «Decenio da Ciencia do Entendemento Global (SDGU) de 2020» e a declaración da nova Cátedra da UNESCO "Entendemento Global para a Sostibilidade".

Para o grupo tamén é fundamental reforzar as redes de colaboración con outras universidades. En primeiro lugar coas universidades brasileiras, coas que se teñen asinado acordos de mobilidade de docentes e alumnos, e coas que se concorre a convocatorias públicas de axuda á investigación. En segundo lugar, con universidades de África Occidental, coas que desde 2009 se ten creado unha rede de cooperación e colaboración para favorecer o fortalecemento, nesta área xeográfica, dos programas educativos do ensino superior con vocación de servizo á sociedade. En terceiro lugar, as relacións científicas con China, en concreto coa Universidade de Zhejiang, para a creación dun China-EU Center for Innovation \& Technology Transference.

A este proceso de internacionalización tamén contribúe de maneira importante o traballo en redes científicas como DARIAH (Digital Research Infraestructure for Arts and Humanities), COST (European network to improve understanding and use of the ground beneath our cities), REGGSILA (Rede de Estudos de Geografia, Género e Sexualidade Ibero Latino-Americana), EAVF (European Association of Vie Francigene), ou RECOT (European Network on Territorial Cooperation), das que os membros do Grupo ANTE forman parte.

II. Intensificar a participación nas convocatorias de proxectos de I+D+I, financiadas pola Unión Europea, o Estado e pola Comunidade Autónoma Galega. Asemade, procurar contratos de investigación con empresas e organismos cos que nunca se tivera traballado anteriormente e concorrer a convocatorias e programas de financiación da investigación que sexan novos para o Grupo. 
III. Mellorar a transferencia dos resultados das investigacións en curso fundamentalmente a través da publicación en revistas de referencia a nivel internacional na nosa área de coñecemento.

Por unha banda, buscarase o aumento da produción científica do grupo publicada en revistas recollidas no Journal Citation Reports (JCR) ou WoS. Por outra, tamén resulta importante incrementar os traballos publicados noutros índices de referencia para as revistas españolas de Ciencias Sociais como o IN-RECS, ou para as publicacións de América Latina, Caribe, Portugal e España, como o Latindex. E, por último, continuarase colaborando con editoriais de prestixio no ámbito das Ciencias Sociais como Springer, Cambridge ou Routledge. Asemade, interesa manter a liña editorial propia iniciada desde o grupo, que persegue publicar resultados da investigación de especial relevancia ou interese a través do Servizo de Publicacións e Intercambio Científico da Universidade de Santiago.

IV. Manter a integración e a colaboración coas actividades científicas e formativas do Departamento de Xeografía, do IDEGA, e do CETUR. Ao mesmo tempo, aumentar a actividade de colaboración co Colexio de Xeógrafos de Galicia, e no marco do agrupamento estratéxico BETA +.

V. Continuar favorecendo a incorporación de xoves á actividade investigadora do grupo, e ao mesmo tempo aumentar o número de doutores do mesmo.

\section{CONCLUSIÓNS}

O "xiro espacial” no coñecemento contemporáneo atopa a súa máxima expresión nas investigacións xeográficas, pois as mesmas abordan temas moi actuais que van desde os problemas ambientais globais ao debate poboacional, dende a desarticulación do medio rural e o descontrol do crecemento urbano ao da artificialización masiva do litoral e a dificultade na súa regulamentación, sen esquecer os impactos paisaxísticos e a conxestión que xera. Tamén o estudo das infraestruturas de transporte ou dos patróns de mobilidade resaltan a centralidade da Xeografía como ciencia social postmoderna.

A raíz da súa actualidade, o saber xeográfico debe levar a un saber atento ao paso do tempo, capaz de afrontar os desafíos, detectar as necesidades da época na que se actúa e procurar as relativas solucións sustentables para a mellora do mundo no que se vive. De feito, a posibilidade de declinar as investigacións xeográficas a distintas escalas é o valor engadido dunha ciencia inevitablemente interdisciplinar. Independentemente da escala dos proxectos que o grupo ANTE levou e leva a cabo (autonómico, nacional e internacional), mantense un compromiso non so coa comunidade científica nos termos de produción e difusión dos novos saberes, senón tamén coa cidadanía. En canto xeógrafos, os temas de debate fan parte da vida cotiá e polo tanto é preciso facilitar reflexións e respostas aos problemas que afronta a nosa sociedade. 
As fontes e as metodoloxías empregadas para lograr estes obxectivos son moi variadas, e adecúanse ás temáticas de referencias. En xeral, o Grupo ANTE ten traballado desde sempre compaxinando metodoloxías cuantitativas e cualitativas. No primeiro caso, os proxectos de investigación e os observatorios turísticos teñen xerado e xeran actualmente datos estatísticos primarios e inéditos que constitúen fontes primarias relevantes para as publicacións, sobre todo nas revistas internacionais cada vez mas esixentes coas orixinalidade das investigacións. No caso das metodoloxías cualitativas, as investigacións diferéncianse entre aquelas que se poderían definir mais tradicionais (revisións bibliográficas, análise da planificación turística e dos estudos de viabilidade, análise de documentos de planificación, entrevistas a actores locais), e outras metodoloxías mais novidosas como por exemplo a Critical Discourse Analysis, as análises visuais, a netnografía, o Sentiment Analysis e o Opinion Mining. Neste sentido faise explícita a necesidade dunha continua formación dos investigadores para estar ao paso coas novas fontes e metodoloxías que as transformacións tecnolóxicas tamén requiren.

A interpretación xeográfica do mundo non pode esquecerse da cartografía, xa que planos e mapas fan parte e determinan en moitos casos as decisións da nosa vida cotián. Por iso, a cartografía e os SIX son ferramentas de traballo moi importantes no grupo ANTE. Aínda que se recoñece na produción dos mapas a mediación humana, no se pode prescindir dos mesmos para entender os acontecementos e os xeitos xeográficos. Esta necesidade fai que a representación cartográfica sexa un punto de forza nos mesmos resultados dos proxectos de investigación e nas publicacións. De feito, pódese afirmar que a produción cartográfica dunha investigación é unha ferramenta estratéxica para facer mais doado entender o tema do estudo, e máis visibles os seus resultados. A tal propósito, o grupo ANTE inviste na formación en SIX, remarcando así a importancia das relacións cos outros colectivos profesionais para a mellora da formación dun perfil investigador, que poda ao mesmo tempo operar no mundo de traballo, no só académico.

Sendo a Xeografía unha ciencia multifacética, polo seu carácter tradicional de coñecemento fronteirizo facilita puntos de contacto con outros ámbitos do saber. Esta necesidade queda reflectida nos consorcios interuniversitarios que desde o grupo ANTE se levan empuxando e, en moitos casos, liderando. Como xa comentado, trátanse de consorcios nacionais e internacionais, que ao mesmo tempo contribúen a mellorar o rendemento de indicadores relativos ao número de proxectos en colaboración con outros grupos estatais ou estranxeiros, e de aí o número de publicacións en colaboración con outros grupos estatais ou estranxeiros. Nese contexto, destaca a coordinación da rede NEDAT, unha rede de investigación interdisciplinar, a través da cal tamén se traballa para mellorar os indicadores de rendemento, no só do grupo, senón da mesma rede.

Captar fondos é unha tarefa complexa, resultado dunha combinación case matemática de indicadores de produtividade que, pola súa natureza cuantitativa, a veces parece priorizar a cantidade máis que a calidade. Polo tanto de cara o futuro existe o compromiso de manter viva a lóxica dun modelo académico cada vez mais competitivo, pero sen comprometer a calidade da investigación. 


\section{BIBLIOGRAFÍA}

Bauman, Z. (1989): La modernidad liquida. México: Fondo de Cultura Económica.

Benach, N. e Albet, A. (2010): Edward Soja. La perspectiva postmoderna de un geógrafo radical. Barcelona: Icaria.

Castells, M. (1974): La cuestión urbana. Madrid: Siglo XXI.

Castells, M. (1995): La ciudad informacional. Tecnologías de la información, reestructuración economica y el proceso urbano-regional. Madrid: Alianza Ed.

Constela Veiga, X. (2018): Colapso Territorial En Galiza-Premio Ramón Piñeiro. Vigo: Galaxia.

Debord, G. (1967): La Société du Spectacle. París: Gallimard.

Deleuze, G. e Guattari, F. (1980): Mille Plateaux. Capitalisme et Schizophrénie II. París: Minuit.

Durán Villa, F. R., Ferrás Sexto, C., Lois González, R. C., e Santos, X. M. (1998): «A propósito del Atlántico como tema de reflexión geográfica. Aproximación temática y bibliográfica a una cuestión escasamente tratada por la Geografía española», Boletín de la Asociación de Geógrafos Españoles, 25, 105-122.

Farinelli, F. (2009): La crisi della ragione cartografica. Turín: Einaudi.

Felicidades-García, J. e Piñeiro-Antelo, M. A. (2017): «Competitividad, Sostenibilidad y Diversificación en la Fachada Atlántica de la Península Ibérica: La Gestión Local del Fondo Europeo de Pesca (2007-2013)», Revista de Estudios Andaluces, vol. 34 (1), 350-379. http://dx.doi.org/10.12795/rea.2017.i34.12

Foucault, M. (1969): L'archéologie du savoir. París: Gallimard.

Foucault, M. (1978): Microphisique du pouvoir. París: Galimard.

Gusman, I., Lopez, L., Lois González, R. C. e Santos, X. M. (2017): «The challenges of the First European Cultural Itinerary: the Way of St. James», AlmaTourism. Journal of Tourism, Culture and Territorial Development, 8(6), 1-19. DOI: 10.6092/ issn.2036-5195/6034

Haersbaert, R. (2010): Regional-Global. Dilemas da Regiâo e da Regionalizaçâo na Gegrafia Contemporânea.

Harvey, D. (1976): «Geografía y Teoría Tevolucionara I y II», Geocrítica. Cuadernos Críticos de Geografía Humana, núms. 3 y 4.

Harvey, D. (1990): La condición de la posmodernidad: investigación sobre los orígenes del cambio cultural. Buenos Aires: Amorrortu.

Harvey, D. (2001): Espacios del capital: hacia una Geografía crítica. Madrid: Akal.

Hobsbawn, E. (1997): On History. Londres: Hachette.

Latour, B. (1993): La Clef de Berlin. Petites leçons de sociologie des sciences. París: La Découverte.

Latour, B. (2015): Face à Gä̈a: Huit conférences sur le Nouveau Régime Climatique. París: La Découverte.

Lefebvre, H. (1974): La production de l'espace. Paris: Anthropos. 
Lois González, R. C. (1999): «La pesca: actividad económica y organización espacial» En R. Galdós Urrutia, e E. Ruiz Urrestarazu (Coords.), Postproductivismo y Medio Ambiente. Perspectivas geográficas sobre el espacio rural (pp. 113-175). IX Coloquio de Geografía Rural. Vitoria-Gasteiz: Departamento de Agricultura y Pesca.

Lois González, R. C. (2013): «The Camino de Santiago and its contemporary renewal: Pilgrims, tourists and territorial identities», Culture and Religion: An Interdisciplinary Journal, 14(1), 8-23. DOI: 10.1080/14755610.2012.756406.

Lois González, R. C.; Castro Fernández e B. Ma; Lopez, L. (2015): «From Sacred Place to Monumental Space: Mobility along the Way to St James», Mobilities, 11(5), 770788. DOI: 10.1080/17450101.2015.1080528.

Lois, R. e Santos Solla, X. M. (2015), «Tourist and pilgrims on their way to Santiago. Motives, Caminos and final destination», Journal of Tourism and Cultural Change, 13(2), 149-164. DOI: 0.1080/14766825.2014.918985.

Lopez, L. (2013): La Imagen de Santiago de Compostela y del Camino en Italia. Una aproximación desde la geografía cultural. Santiago de Compostela. Disponible en:http://dspace.usc.es/handle/10347/7111.

Lopez, L., Lois Gonzalez, R. e Santomil Mosquera (2015): «Film-Induced Tourism in the Way of Saint James», Almatourism - Journal of Tourism, Culture and Territorial Development, 6(4), 18-34. DOI: 10.6092/issn.2036-5195/4951.

Lopez, L., Lois Gonzáléz, R. C. e Castro Fernández, B. M. (2017): «Spiritual Tourism on The Way of Saint James. The Current Situation», Tourism Management Perspectives, 14, 225-234. DOI: 10.1016/j.tmp.2017.07.015.

Lopez, L. e Lois González, R. C. (2017): «The Voices of Female Pilgrims in Medieval Wills. The Jacobean Devotion In Apulia (Italy)», Gender, Place \& Culture, 24(4), 482-498.DOI: 10.1080/0966369X.2017.1334630.

Marques Pereira, M. N. (2014): Sistemas de Información Xeográfica e realidade aumentada en Turismo: Guía interactiva do Camiño Portugués de Santiago en Barcelos (2014). Tese Doutoral. Disponible en:

https://citius.usc.es/investigacion/publicacions/listado/sistemas-informacao-geografica-realidade-aumentada-em

Nogué, J. (2018): Yi-Fu Tuan. El arte de la geografía. Barcelona: Icaria.

Ortega Valcárcel, J. (2000): Los horizontes de la Geografia. Teoría de la geografía. Barcelona: Ariel.

Piñeiro Antelo, M. A. e Lois González, R. C. (2018): «La investigación de la actividad pesquera y marítima: un análisis a través de las revistas españolas de Geografía (1950-2015)», Boletín de la Asociación de Geógrafos Españoles, 77, 315-334. DOI: 10.21138/bage.2543

Piñeiro Antelo, M. Á., Durán Villa, F. R. e Santos, X. M. (2018): «Inmigración peruana y pesca en el puerto de Cambados (Galicia): una perspectiva de género», Boletín de la Asociación de Geógrafos Españoles, 76, 218-246. DOI: 10.21138/bage.2521 
Piñeiro, M. A., Felicidades, J. e O’Keeffe, B. (2018): «Multifunctional Fishing Areas in Policy and Practice. A Comparative Analysis of Spain and Ireland», Infinite Rural Systems in a Finite Planet: Bridging Gaps towards Sustainability. Santiago de Compostela: Universidade de Santiago Publicacións, pp. 123-130

Revkin, A. (1992): Global Warming: Understanding the Forecast. New York: Abbeville Press.

Ruddiman, W.F. (2003): «The Anthropogenic Greenhouse Era Began Thousands of Years Ago», Climate Change, 61, 261-293.

Santomil Mosquera, D. (2012): A imaxe exterior de Galiza no século XXI. Servicio de Publicación de la Universidad de Santiago de Compostela, Santiago de Compostela. Disponible en: http://dspace.usc.es/handle/10347/3654

Santos, M. (1996): De la totalidad al lugar. Barcelona: Oikos-Tau.

Santos Solla, X. M. (2001): «La explotación de los recursos marinos: pesca, acuicultura y marisqueo». In Actas del XV Congreso de Geógrafos Españoles Los Espacios litorales y emergentes (pp. 213-254). Santiago de Compostela: Servicio de Publicaciones de la Universidad de Santiago.

Sassen, S. (1991): The global city. New York, London, Tokyo. Princeton (NJ): Princeton University Press.

Soja, E. (1989): Postmodern Geographies. The Reassertion of Space in Critical Social Theory. Londres: Verso.

Soja, E. (1996): Thridspace Journeys to Los Angeles and Other Real-and-Imaginaded Places. Oxford \& Cambridge: Blackwell.

Taboada de Zuñiga, P. (2014): O Turismo Idiomático en Santiago de Compostela. Universidade de Santiago de Compostela. Tese Doutoral. Disponible en: https://minerva. usc.es/xmlui/bitstream/10347/12391/1/rep_801.pdf.

Taylor, P. J.(1994): Geografía política. Economía-mundo, Estado-nación y Localidad. Madrid: Trama.

Tuan, Y. F. (1974): Topophilia: a study of environmental perception, attitudes, and values. 1974. Englewood Cliffs (NJ): Prentuce-Hall.

Tuan, Y. F. (1977): Space and Place: The Perspective of Experience. Minneapolis (MN): Minesotta University Press.

Tuan, Y. F. (1998): Escapism. Baltimore (MD): John Hopkinks University Press.

Willians, R. (1980): Problems in Materialism and Culture: Selected Essays. London and New York: Verso.

Zoido, F. et al. (2013): Diccionario de Urbanismo, Geografía urbana y Ordenación del Territorio. Madrid: Cátedra. 